\title{
Effects of Preparation to Enhance Japanese University Students' Participation in ELF Dyadic Discussions
}

\author{
Hanako Itsubo *, Kae Nakaya ${ }^{\dagger}$, Yuhei Yamauchi ${ }^{*}$
}

\begin{abstract}
The recent trend of computer-assisted language learning (CALL) research expects second language learners to actively participate in conversations as global citizens. In this so-called ecological CALL environment, it is common to use English as Lingua Franca (ELF), but because the participants have different levels of language proficiency, it can be difficult for less proficient learners to fully participate in the conversation. A similar problem is pointed out in the field of English Medium Instruction (EMI). Willingness to Communicate (WTC) is a concept that can affect learners' participation in ELF conversations. This research focuses on state WTC and evaluates whether considering the topic content in their native language (i.e., Japanese) before ELF dyadic discussions results in increased utterances by local students. An experiment was conducted with 20 participants from a university in Japan, each of whom was paired with an international student. Participants were divided into two groups: the experimental group focused on the content of the topic in Japanese, while the control group studied English phrases and vocabulary before discussions. A subsequent $t$-test, calculation of effect size, and analysis of the participants' use of communication strategies implied that focusing on topic content in Japanese was to some extent, more effective.
\end{abstract}

Keywords: Communication Strategies, English as a Lingua Franca, English Medium Instruction, Willingness to Communicate

\section{Introduction}

There have been some changes in the trend of computer-assisted language learning (CALL) research over time. Chun [1] proposed the fourth stage of CALL starting in the 2010s in addition to Warschauer's [2] three stages capturing the changes in the CALL trend. In the fourth "ecological CALL" stage, language learners are expected to autonomously use learning opportunities in multilingual contexts and actively participate in conversations with their identities as global citizens [1]. Language learners in recent years need to develop not only linguistic communicative competence but also all kinds of skills and social practices that are required to be productive members of civic society [3].

\footnotetext{
${ }^{*}$ The University of Tokyo, Tokyo, Japan

$\dagger$ Tokyo Institute of Technology, Tokyo, Japan
} 
Within this ecological CALL stream, researchers have focused on the effect of technology on intercultural communication and found that technology-enhanced environments have positive effects on affective factors such as motivation and attitudes towards communication [4] [5] [6]. For example, Zheng et al. [4] observed that students who were involved in online virtual world communication with native English speakers had higher self-efficacy and attitudes toward the use of English compared to those who did not engage in the activity. Meanwhile, Vinther [5] examined the effect of sharing cultural narratives through email exchanges between Chinese and Danish university students, all of whom were non-native English speakers, and found improvement in students' motivation in language learning. Chen and Yang [6] also investigated the effectiveness of an online project with participants from five different countries and concluded that it had an impact on learners' development of motivational and critical disposition toward cultural and language learning. These studies indicate the possibility of technology working as a catalyst in enhancing intercultural collaborative communication and developing learners' cross-cultural communicative competence including their attitudes over weeks of intervention.

In an ecological CALL environment, it is common to use English as Lingua Franca (ELF) as a means of communication. One of the challenges in ELF conversations is that because participants have different levels of English language proficiency, it can be difficult for less proficient learners to fully participate in the conversation. Willingness to Communicate (WTC) is an important concept when focusing on this issue. Dörnyei [7] has mentioned that although second language (L2) communicative competence is a powerful variable of one's predisposition toward or away from communication, "there are many L2 learners who are very competent L2 speakers yet tend to avoid L2 communication situations, whereas some other, less proficient learners actively seek opportunities to engage in L2 talk" (p.12). Thus, the researchers argue that there is a need to consider learners' WTC. According to previous studies, the use of technology has positive effects on the stable, trait-like WTC [8] [9], and state WTC, which fluctuates on the spot [10] [11]. When we take a closer look at these studies, it is possible to say that technology helps learners to have a higher WTC by providing more collaborative environments and personalizing the conversation topics. These studies adjust the environment to make sure the learners have things that they are willing to communicate with their interlocutors regarding the topic. However, it is also important to identify how to encourage them to have things to communicate ahead of conversation to increase their state WTC, especially in person-to-person communications. There is not enough discussion on the content of preparation to enable them to have things to communicate and how this preparation affects the conversation.

This study attempts to investigate short-term interventions that increase participants' state WTC by focusing on the content of learning material used in preparing for conversation. As a first step, face-to-face experiments have been carried out, which will also hold implications for ecological CALL environments. In addition, recent initiatives of Japan's MEXT have sought to promote English medium instruction (EMI) courses at Japanese universities to internationalize higher education in Japan [12]. In EMI, which is defined as "the use of the English language to teach academic subjects in countries or jurisdictions where the first language (L1) of the majority of the population is not English" (p.4) [13], the issue of local students' tendency to stay silent and not participate in classroom discussions has been noted in previous studies [14]. The authors conducted the experiment in an environment similar to the EMI environment in Japan to provide suggestions not only to CALL but also to EMI environments. 


\section{Literature Review}

WTC was originally proposed in the field of L1 communication studies [15] [16] and introduced into the L2 setting by MacIntyre et al. [17], who defined WTC as "a readiness to enter into discourse at a particular time with a specific person or persons, using a L2" (p.547). MacIntyre et al. [17] suggested a heuristic pyramid model for a WTC (Figure 1).

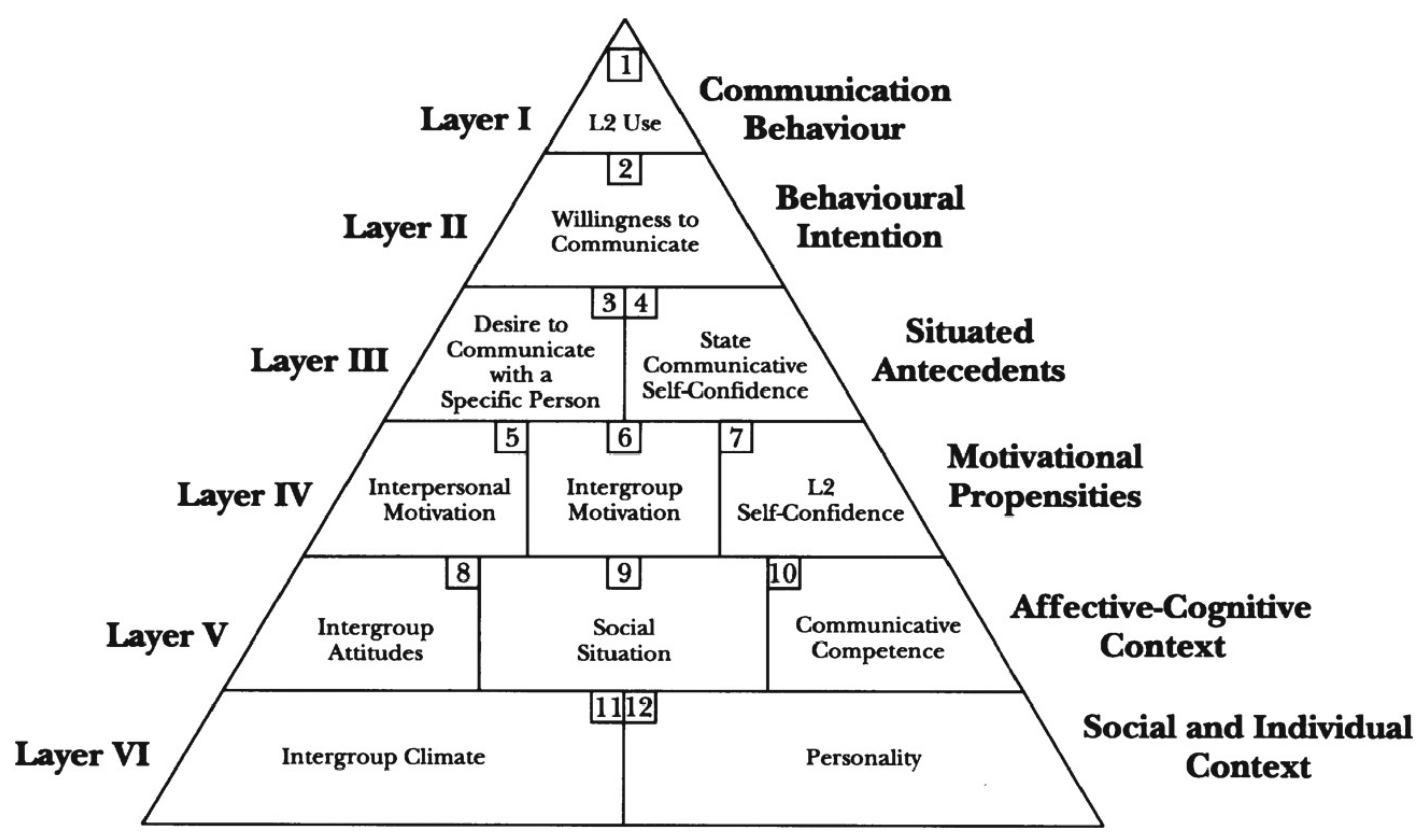

Figure 1: MacIntyre et al. [17]'s heuristic pyramid model of WTC (p.547)

As shown in the figure, this model views WTC as a concept affected by psychological, linguistic, and social variables. Layers I to III include contextual variables such as L2 use, L2 WTC, desire to communicate with a specific person, and state communicative self-confidence. Layers IV to VI are concerned with more stable, trait-like variables including interpersonal motivation, intergroup motivation, L2 self-confidence, intergroup attitudes, social situation, communicative competence, intergroup climate, and personality. This model displays "dual characteristics at both trait and state level" (p.835) [18], where trait WTC reflects general communicative tendencies rooted in an individual's personality, and state WTC reflects the individual's communicative behaviors fluctuating across time and situations [19]. 
In Japan, existing intervention studies are usually designed to increase trait WTC through classes that last for a few weeks to half a year, and the change in WTC is measured by questionnaires at the beginning and end of the intervention period [20] [21] [22]. However, this paper will focus on state WTC rather than on trait WTC because it would be important in the case of EMI classrooms to maximize the state WTC in a short-term intervention to prevent students from losing their learning opportunities in each class where new academic content is taught. From a global perspective, although previous research has primarily focused on the WTC's stable trait dispositions in the bottom layers, many recent studies globally have focused on WTC at the state level [23] [24] [25] [26] [27]. After systematically reviewing 35 research papers on state WTC, Zhang et al. [19] proposed a framework combining the situational antecedents of WTC (Figure 2).

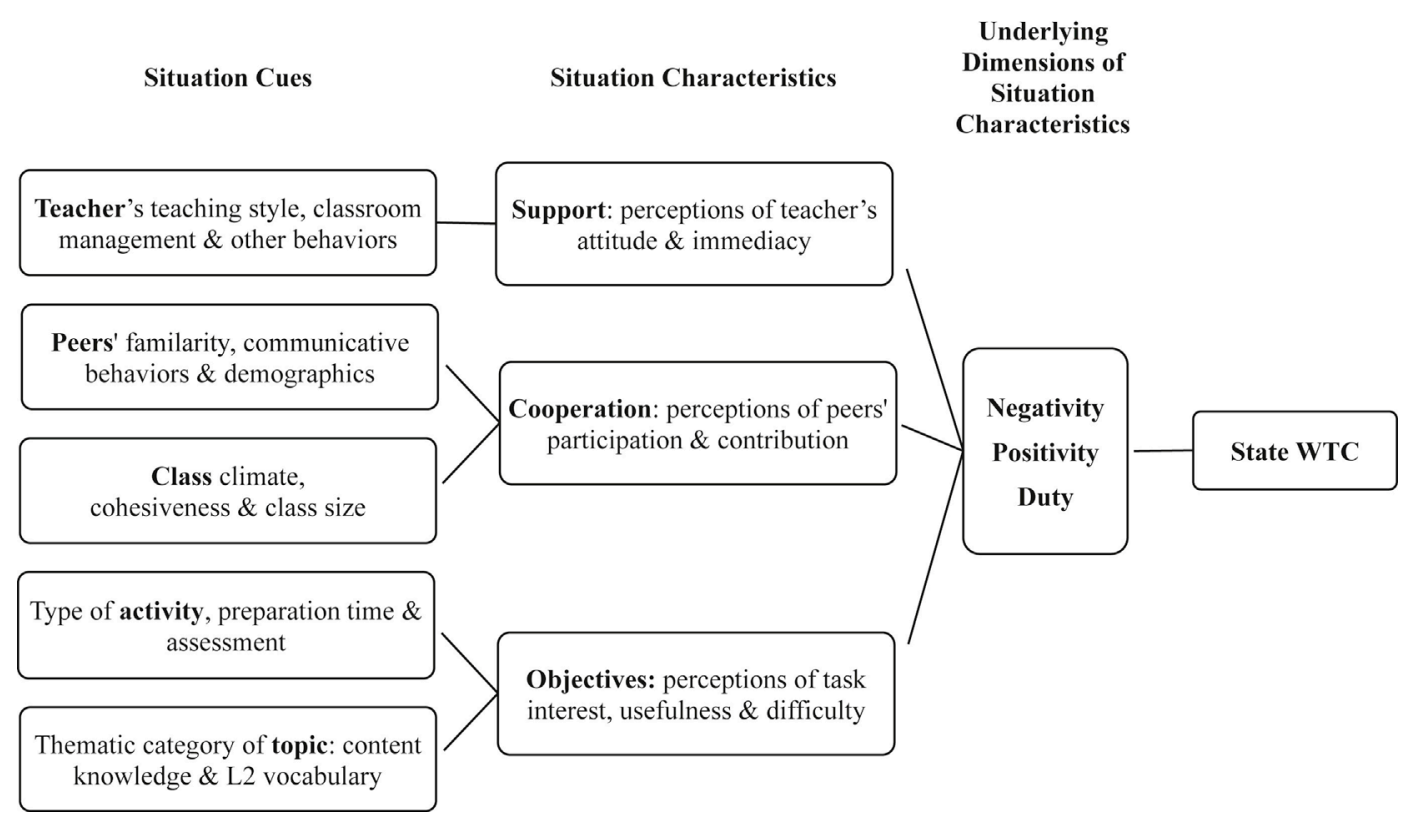

Figure 2: Zhang et al. [19]'s framework for situational antecedents of WTC (p.233)

Figure 2 shows three interlinked layers of situational variables: situation cues (objective features of situations), situation characteristics (subjective features of situations), and underlying dimensions of situation characteristics (i.e., negativity, positivity, and duty). Although further studies are required to test the validity of this framework, as it constitutes the first attempt to organize the situational antecedents of WTC, Zhang et al. [19] shed light on the different types of situational variables, especially on relatively under-explored situation characteristics.

The situation characteristics are summarized into three factors: support, cooperation, and objectives. Support refers to students' perception of a teacher's attitude and immediacy. This is based on situation cues related to teachers, such as teaching style and classroom management. This includes time for task preparation, topic selection, error correction, and other verbal and non-verbal behaviors, including nodding, smiling, and feedback. Cooperation refers to a student's perception of his/her peers' and the interlocutors' participation and contribution. Whole-class activities are affected by factors such as class cohesiveness, classroom climate, and class size; in 
dyadic and group activities, the interlocutors' communicative behaviors, demographic features such as gender, ethnicity, and L2 proficiency, and the relationship between the student and the interlocutor may act as influencing factors. Objectives refer to a student's perception of tasks, of which task-interest, task-usefulness, and task-difficulty are considered important. They are based on situation cues related to the activity, including the type of activity (e.g., dyadic, group, or whole-class), task preparation time, and assessment. Another situation cue here is the thematic category of topics which highlights the relevance of content knowledge and topic-related L2 vocabulary to task perception.

This study seeks an effective way of implementing the findings of this situational WTC model by examining the effects of intervention. Of the 35 papers that Zhang et al. [19] examined, only four studies involved intervention experiments [26] [27] [28] [29]. These studies revealed, respectively, the effects of out-of-class speaking practice, online chatting, class sizes, and the interlocutors' WTC levels on the learners' WTC.

According to Figure 2, one of the situation characteristics that affect state WTC is the learner's perception of tasks, which is influenced by factors such as content knowledge and preparation time. In conventional classes, many students are made to study and practice English in order to use the language verbally, but the above model also suggests the importance of focusing on topic content. The four experimental studies previously mentioned did not check the effect of topic content or what to do during the preparation time prior to face-to-face conversation. Therefore, we defined the research question addressed in this study as follows:

Does the amount of utterance in ELF increase when the learner prepares for discussion by considering the topic content in their native language beforehand?

Since the previous studies examined by Zhang et al. [19] mainly focused on university-level English learners, the authors would like to examine the above research question in the context of English learners in Japanese universities conducting dyadic conversations with international students.

\section{Method}

The authors conducted an experiment to examine the effect of preparing for conversations by considering the topic content in their native language. The participants were 20 non-English major students studying at a private university in Japan. Six of them were seniors, two were juniors, seven were sophomores, and five were freshmen. All of them belonged to a specific seminar and regularly carried out fieldwork for their research. They were divided into two groups: an experimental group where the participants prepared for the conversation by considering the topic in Japanese, and a control group where the participants prepared by studying English phrases and vocabulary items. Each participant was paired with an interlocutor, an international student studying at a Japanese university, for conversations in English. The details of the experiment are provided in the following sections.

\subsection{Discussion topic}

Based on Zhang et al. [19], the discussion topic was chosen to fulfill three criteria: taskconfidence, task-interest, and task-usefulness. In order to make the participants feel task-interest 
and task-usefulness, a preliminary survey was carried out asking the students in the seminar for a topic based on the issues they encountered during their fieldwork. One of the topics they suggested was chosen for the discussion topic in the experiment, which concerned the evaluation of project activity in the field. The actual list of questions provided to the participants and interlocutors is as follows:

Q1. Is it necessary to evaluate the effect of the project's activity on the people (e.g., children, students from junior/middle/high schools, local people in the target region) who were involved in the project?

Q2. Why is it better to evaluate this effect? Or else, why is it better not to?

Q3. If we are to use evaluation to enable more people to understand the project activity, what do we have to pay attention to?

\subsection{Procedure}

At the beginning of the experiment, an explanation was given to all participants and interlocutors, and written informed consent was obtained from each participant and interlocutor.

Participants were divided into two groups: the experimental group used their preparation time to consider and think reflectively on the content of the topic in Japanese, and the control group studied English phrases and vocabulary that could be used in the conversation. The group members were arranged so that the scores of the control variables were almost equal between the experimental "Content Group" and control "English Group." The distribution of control variable scores in each group is summarized in Table 1, while the details are explained in Section 3.3.

Table 1: Control variables in each group

\begin{tabular}{|c|c|c|c|c|}
\hline \multirow{2}{*}{} & \multicolumn{2}{|c|}{ Content Group } & \multicolumn{2}{c|}{ English Group } \\
\cline { 2 - 5 } & Mean & $S D$ & Mean & $S D$ \\
\hline $\begin{array}{c}\text { WTC } \\
\text { (English) }\end{array}$ & 28.4 & 8.8 & 30.2 & 7.7 \\
\hline $\begin{array}{c}\text { WTC } \\
\text { (Japanese) }\end{array}$ & 37.5 & 7.09 & 42.6 & 5.89 \\
\hline $\begin{array}{c}\text { International } \\
\text { Posture }\end{array}$ & 82.5 & 12.0 & 85.7 & 18.1 \\
\hline $\begin{array}{c}\text { CEFR } \\
\text { (Rating A1 as } \\
1 \text { and C2 as } \\
\text { 6) }\end{array}$ & 3.4 & 0.74 & 3.4 & 0.62 \\
\hline
\end{tabular}

The Participants had a preparation time of 30 minutes. Members of the experimental group (Content Group) considered the content of the discussion topic by writing down the answers to the following questions in Japanese on a piece of A4 paper:

1. What kind of changes do you expect to see in the people involved in your project activities? 
2. Please provide examples of the speech and/or actions of the people involved in the project activities that made you feel their changes and progresses.

3. Please write down some ideas to make not only you but also other people see the changes you mentioned in Q2.

4. What are your concerns when you try to evaluate your project activity?

Members of the control group (English Group) studied a list of English phrases and vocabulary items on a piece of A4 paper created based on Fujii and Nomura [30] and Hinata and Kano [31], which could be useful for English conversations and presentations. The English group members followed the instructions below:

1. Please write down the phrases you think would be useful in the following conversation.

2. Please search for phrases and vocabulary that might be useful in the conversation with the international exchange students using your smartphones and write them down.

The topics of discussion were not directly presented to either group during the preparation time.

Meanwhile, the interlocutors were given the following instructions together with a simple explanation of the projects in the participants' seminar:

"Your mission today is to complete the task while being a good interlocutor for your partner. To let your partner speak up in English,

- Please ask your partner many questions during your conversation.

- Please feel free to share your ideas.

- Please tell them about conflicting ideas, too.

- Please use easy words, speak slowly, and change your wording when they look confused.

- You cannot use Japanese, but you can try anything else to communicate."

Conversation in pairs lasted for 45 minutes, where the first three minutes were used for selfintroduction, since the paired participants and interlocutors had never met each other before. The number of utterances of the participants and interlocutors in each pair was measured during the 42 minute-discussion.

\subsection{Details about the participants and their interlocutors}

The participants who volunteered to participate in the experiment were members of a specific seminar at the university that discussed education and intercultural communication. Nineteen were Japanese and one was Chinese, all of whom were native Japanese speakers. They were asked to fill out the questionnaire online using Google Form prior to the experiment to collect their basic information including their year at the university, number of semesters they have taken, TOEIC/TOEFL/Eiken scores, and overseas experience. TOEIC/TOEFL/Eiken scores were converted into a scale of 1 to 6 based on the Common European Framework of Reference for Languages (CEFR) using a document provided by MEXT [32]. CEFR provides a set of common reference levels (A1 to C2) that determined language proficiency [33]. WTC scores in English and Japanese, and scores for international posture were also monitored by asking the participants to answer the questionnaires from Yashima [34] after their translation into Japanese.

The participants' interlocutors were 20 international students who had come to Japan to study at Japanese universities and volunteered to participate in the experiment as interlocutors by applying 
through the Google form posted in the groups for international students on Facebook. A total of 32 applications were received, with the first 22 applicants being asked to participate in the experiment. The condition for applying was that they could speak English fluently. All the interlocutors were either native speakers of English or had spent more than five years at Englishmedium schools. The nations of origin of the interlocutors included China, Korea, the USA, Indonesia, Morocco, India, Turkey, Australia, and Japan. There were two interlocutors of Japanese nationality, who were considered eligible to participate in the experiment as interlocutors since they were native speakers of English and were born and raised abroad.

\subsection{Data collection and data analysis}

A voice recorder was placed on the desk in front of each pair to record their conversations. Two video cameras were placed at the top left and bottom right corners of the classroom to record the movements of each pair, including their gestures during the conversation.

For data analysis, the recorded conversation data of the 42-minute discussion, excluding the 3minute self-introduction, were first transcribed by the first author. The transcripts included words used to fill the gaps in utterances or "filler words" [35], such as "ah", "uh", "um" and "like". Although fillers traditionally have been ignored as "insignificant noise" (p.27) [36], this research considered their use as type of communication strategy that played a part in the communication resulting from the participants' WTC, as Dörnyei [37] included the use of fillers in the list of communication strategies.

The number of words spoken by the participant and interlocutor was then counted, and the total number of words spoken by each pair was calculated based on the transcript using the word count function in Google Document. Some participants used Japanese words as communication strategies which were included in the count. The ratio of each participant's utterance in the pair was also calculated by dividing the number of spoken words by the total number of words spoken by each pair.

\section{Results}

Table 2 shows a comparison of the means of the participants' utterances between the two groups found in the experiment.

Table 2: Comparison of the participants' mean utterances by group

\begin{tabular}{|c|c|c|c|c|}
\hline \multirow{2}{*}{} & \multicolumn{2}{|c|}{ Content Group } & \multicolumn{2}{c|}{ English Group } \\
\cline { 2 - 5 } & Mean & $S D$ & Mean & $S D$ \\
\hline $\begin{array}{c}\text { Number of words } \\
\text { spoken by participant } \\
\text { in 42 minutes }\end{array}$ & 1870 & 785.8 & 1534 & 878.7 \\
\hline $\begin{array}{c}\text { Ratio of participant's } \\
\text { utterance in the pair }\end{array}$ & 0.477 & 0.179 & 0.410 & 0.197 \\
\hline
\end{tabular}


The mean number of words spoken by the participants in 42 minutes was 336 words greater in the Content group, and the mean value for the ratio of participants' utterances in the pair was 0.067 points higher in the Content group. To identify whether there were any significant differences in the means of participants' utterances between the Content and English groups, the Shapiro-Wilk test was first performed to test normality. For both the number of words spoken by the participants and the ratio of participants' utterances in pairs, it was confirmed that the data for both the Content and English groups followed a normal distribution with $p>0.05$. Second, Levene's test was performed on both data to check for equality of variance. The results were that homoscedasticity was assumed with $p>0.05$, for both the number of words spoken by the participants and the ratio of participants' utterances in pairs. Therefore, an independent samples $t$-test was performed. No significant difference was found in the number of words spoken $(t(18)$ $=-0.901, p=0.379)$ or the ratio of participants' utterances in the pair $(t(18)=-0.799, p=0.435)$.

The effect size was calculated based on Mizumoto and Takeuchi [38]. For the number of words spoken by participants, the effect size was considered to be small to medium $(d=0.40)$, as was the effect size for the ratio of participants' utterances in the pair $(d=0.36)$.

\section{Discussion}

The results showed that the differences in values were not statistically significant. However, some participants seemed to be attempting to speak in English when they took some time to search for a word to express what they wanted to say and stayed silent to figure out the vocabulary. Although these actions can be considered to show their willingness to communicate, they reduce the number of utterances as a result. Therefore, the authors decided to analyze these actions.

Some participants' actions displaying struggles while talking are considered part of communication strategies (CSs). The definition of CSs varies between researchers, but this paper considers them as a relatively broad concept, with reference to Dörnyei [37]'s definition that CSs "cover a wide range of communication-enhancing devices" (p. 60). Nevertheless, the basic concept of CSs is adopted from Canale and Swain [39]'s well-known definition: "verbal and nonverbal strategies that may be called into action to compensate for breakdowns in communication due to performance variables or to insufficient competence" (p. 30).

Færch and Kasper [40] posited two major categories of CSs: reduction and achievement strategies, where the former is used to renounce the original communication goal and the latter attempts to maintain the original goal in an alternative way. Achievement strategies may reflect the participants' positive attitude toward the conversation, which sometimes does not directly result in an increase in the number of utterances because of restrictions in their language proficiency, such as the limited size of their vocabulary. Therefore, this study uses Fang's [41] categorization of achievement strategies as a coding framework for the CSs used by the participants, as shown below. 
Table 3: List of communication strategies based on Fang [41]

\begin{tabular}{|c|c|c|c|}
\hline & Category group & Category & Definition \\
\hline \multirow{8}{*}{$\begin{array}{l}\text { Self- } \\
\text { Problem } \\
\text { Solving }\end{array}$} & \multirow{4}{*}{ Code } & Word-borrowing & Code-switching to L1/L3 \\
\hline & & Literal translation & $\begin{array}{l}\text { Literally translating phrases in L1 into } \\
\text { L2 }\end{array}$ \\
\hline & & Foreignization & $\begin{array}{l}\text { Adjusting L1 phonologically/ } \\
\text { morphologically }\end{array}$ \\
\hline & & Word-coinage & $\begin{array}{l}\text { Creating new words that do not exist } \\
\text { in L1/L2 }\end{array}$ \\
\hline & \multirow{4}{*}{ Concept } & $\begin{array}{l}\text { Repetition of a } \\
\text { word }\end{array}$ & $\begin{array}{l}\text { Emphasizing the meaning of the word } \\
\text { presenting difficulty by repeating it }\end{array}$ \\
\hline & & Replacement & $\begin{array}{l}\text { Replacing the word presenting } \\
\text { difficulty by other } \\
\text { 1. Vocabulary } \\
\text { 2. Examples } \\
\text { 3. Explanations }\end{array}$ \\
\hline & & Reconstruction & $\begin{array}{l}\text { Correcting the words based on what } \\
\text { he/she wants to say }\end{array}$ \\
\hline & & Explanation & $\begin{array}{l}\text { Adding explanation to the uncertain } \\
\text { word }\end{array}$ \\
\hline \multirow{8}{*}{$\begin{array}{l}\text { Joint- } \\
\text { Problem } \\
\text { Solving }\end{array}$} & \multirow[b]{2}{*}{$\begin{array}{l}\text { Requesting } \\
\text { completion }\end{array}$} & Direct appeal & Asking directly for the help \\
\hline & & Indirect appeal & $\begin{array}{l}\text { 1. Using words such as "sorry", and } \\
\text { "excuse me" to show the difficulty } \\
\text { 2. Using stalling words to request for } \\
\text { help }\end{array}$ \\
\hline & \multirow{2}{*}{$\begin{array}{l}\text { Requesting } \\
\text { confirmation }\end{array}$} & $\begin{array}{c}\text { Requesting } \\
\text { vocabulary check }\end{array}$ & $\begin{array}{l}\text { Using rising intonation to check } \\
\text { whether the interlocutor understood } \\
\text { the vocabulary used }\end{array}$ \\
\hline & & $\begin{array}{l}\text { Requesting } \\
\text { understanding } \\
\text { check }\end{array}$ & $\begin{array}{l}\text { Checking whether the interlocutor } \\
\text { understood what he/she wanted to say }\end{array}$ \\
\hline & $\begin{array}{c}\text { Fostering } \\
\text { understanding }\end{array}$ & Asking to repeat & $\begin{array}{l}\text { Asking to repeat what he/she could not } \\
\text { catch }\end{array}$ \\
\hline & \multirow[b]{3}{*}{ Non-linguistic } & Illustration & Drawing illustrations or letters \\
\hline & & Gesture & Mimicking, using gestures \\
\hline & & $\begin{array}{l}\text { Facial expressions } \\
\text { and gestures } \\
\text { showing difficulties }\end{array}$ & $\begin{array}{l}\text { Make intentional eye contact or frown } \\
\text { to show that he/she is facing some } \\
\text { difficulties }\end{array}$ \\
\hline
\end{tabular}

"Word-coinage" and "facial expressions and gestures showing difficulties" were removed from the coding categories since "word-coinage" was not used in any conversation, and "facial expressions showing difficulties" were not captured by the video cameras. Instead, two new categories were introduced: "use of translator," in which the participants use Google Translate, etc., to communicate what they want to say, and "time gaining strategies", in which the participants ask their interlocutors to wait so that they can gain some time to find an appropriate 
expression. "Use of translator" was placed under the category group of "code" and a new category group called "time-gaining" was created for "time-gaining strategies" because "timegaining strategies" did not seem to fit into any of the existing category groups.

In the actual procedure, the first author counted the number of CSs used based on the transcript. When the participant used more than one strategy in one sentence, it was counted in all corresponding coding categories. Some participants' voices were sometimes so low that they were considered to be talking to themselves, and those utterances were not analyzed because they were not considered to communicate with their interlocutors.

Table 4 shows a comparison of the total number of CSs used by the participants between the two groups.

Table 4: Comparison of the total number of communication strategies used by the participants between two groups

\begin{tabular}{|c|c|c|}
\hline Types of CSs & Content Group & English Group \\
\hline Code & 48 & 152 \\
\hline Concept & 105 & 75 \\
\hline Time-gaining & 10 & 22 \\
\hline Requesting completion & 30 & 10 \\
\hline Requesting confirmation & 30 & 53 \\
\hline Fostering understanding & 52 & 71 \\
\hline Non-linguistic & 10 & 10 \\
\hline
\end{tabular}

As shown in Table 4, the content group used more CSs from the category of "Concept," where they tried to explain or replace the word in English when they did not know the right vocabulary, while the English group used more "Code" CSs, where they code-switched to their L1 (Japanese) when encountering difficulties. This indicates that although there were some participants in the Content group who did not produce high number of utterances as the authors expected, they showed an effort to speak in English, reflecting their L2 WTC. 
Some examples of conversations carried out by the Content group participants are as follows.

Excerpt 1
\begin{tabular}{|l|l|l|}
\hline Turn & Speaker & Conversation \\
\hline 7 & Participant I & $\begin{array}{l}\text { My topic is, my opinion is, nante iun darou (how do I say this), } \\
\text { this is my big and so future change but this is recently change is, } \\
\text { ah, someone get... }\end{array}$ \\
\hline 8 & Interlocutor I & Confidence, yes. \\
\hline 9 & Participant I & Confidence and rewarding? \\
\hline 10 & Interlocutor I & Yes, yes. I know. \\
\hline & Participant I & $\begin{array}{l}\text { Rewarding? Nante iuno (how do I say), rewarding? The feel does } \\
\text { and gets motivating for life. Then life and big and so future change }\end{array}$ \\
$\begin{array}{l}\text { do I say this), people think, so people wants to change their } \\
\text { country or... }\end{array}$ \\
\hline 12 & Interlocutor I & Change their lives? \\
\hline
\end{tabular}

Excerpt 2

\begin{tabular}{|l|l|l|}
\hline Turn & Speaker & Conversation \\
\hline 235 & Participant G & $\begin{array}{l}\text { Yeah, that's one of the things we do. We really want to keep the } \\
\text { junior high school to, to, I don't know what it's called, but if there } \\
\text { is no student in school, the school will be gone, right? }\end{array}$ \\
\hline
\end{tabular}

Excerpt 3

\begin{tabular}{|l|l|l|}
\hline Turn & Speaker & Conversation \\
\hline 127 & Participant F & $\begin{array}{l}\text { If, if we have good, nandarouna (what is it), if we have clear reason, } \\
\text { it is... }\end{array}$ \\
\hline 128 & Interlocutor F & Clear reason? \\
\hline 129 & Participant F & $\begin{array}{l}\text { It becomes, became, it becomes easy to, nandarouna (what is it), } \\
\text { tell, tell other people that it's good. }\end{array}$ \\
\hline
\end{tabular}

As for Participant I in Excerpt 1, she was trying to explain the changes she could see in the people involved in the project. She repeated different English words with similar meanings to fully explain her thoughts with her limited vocabulary. As for Participant $G$ in Excerpt 2, she wanted to talk about the closing down of a school due to the decreasing number of students. Since there is a specific word for it in Japanese, Participant $G$ was trying to translate the word directly into English. The participant added some explanation in English to express what she wanted to say as a result of not finding the appropriate English word from her lexicon. As for Participant $\mathrm{F}$ in Excerpt 3, he explained the reason for evaluating the activity and reconstructed his speech by correcting the wording. They all had limited vocabulary, which made it difficult for them to express what they wanted to say. However, they consistently attempted to understand how to 
communicate their ideas in English.

Following are the excerpts from the conversations of English group participants.

Excerpt 4

\begin{tabular}{|l|l|l|}
\hline Turn & Speaker & Conversation \\
\hline 156 & Participant $\mathrm{O}$ & $\begin{array}{l}\text { Nanka hontoni project shite hoshiika wakaranai kara, katteni } \\
\text { evaluation suruno wa chigaukana mitaina (We don't really know }\end{array}$ \\
$\begin{array}{l}\text { whether they want the project or not, so deciding to do evaluation } \\
\text { by my own does not seem right). }\end{array}$ \\
\hline
\end{tabular}

Excerpt 5

\begin{tabular}{|l|l|l|}
\hline Turn & Speaker & Conversation \\
\hline 255 & Interlocutor R & Hm what's the problem in Numazu? \\
\hline 256 & Participant R & Ah, shima hodo dewa nai (it is not as bad as the island). \\
\hline 257 & Interlocutor R & It's not like island? \\
\hline 258 & Participant R & $\begin{array}{l}\text { It's not like island but also have problem that less, less children. } \\
\text { More otoshiyori (elder people). }\end{array}$ \\
\hline
\end{tabular}

Excerpt 6

\begin{tabular}{|l|l|l|}
\hline Turn & Speaker & Conversation \\
\hline 18 & Participant L & $\begin{array}{l}\text { Ah, yes. eeh, watashi wa(I am), eeh, matte matte matte (wait wait } \\
\text { wait). }\end{array}$ \\
\hline 19 & Interlocutor L & Just try to say a word. What do you want to say? Just write. \\
\hline 20 & Participant L & $\begin{array}{l}\text { Just write, okay. Watashiga shougakusei (I was an elementary } \\
\text { school student)... }\end{array}$ \\
\hline 21 & Interlocutor L & So when you were in lower school, primary school? \\
\hline 22 & Participant L & $\begin{array}{l}\text { Yes, yes. Primary school about four? Four year? Yonensei (4th } \\
\text { grade). }\end{array}$ \\
\hline 23 & Interlocutor L & 4th grade, 4th grade. \\
\hline 24 & Participant L & 4th grade no toki (when I was in the 4th grade). \\
\hline
\end{tabular}

As for Participant $\mathrm{O}$ in Excerpt 4, her sentence was completely in Japanese, with an English accent on "project" and "evaluation." Participant R in Excerpt 5 sometimes used Japanese during the conversation, even for phrases that seemed not so difficult for him. As for Participant $\mathrm{L}$ in Excerpt 6, she frequently used the code-switching strategy between Japanese and English. Although people occasionally have no choice but to use their first language to communicate what they want to say, one feature of these excerpts is that some of the participants were reluctant to use English.

\section{Conclusion}

This study investigated whether the number of utterances in English increases when the learner prepares for discussion by considering the topic content in their native language. By using an 
experimental research design with two groups of university students in Japan, no significant difference was observed in the performed independent samples $t$-test for the number of words spoken by the participants and the ratio of participants' utterances in the pair within the 42 minutediscussion. However, the fact that the calculated effect sizes for these values were found to be small-to-medium and the observation of the CSs suggests that the intervention might have motivated state WTC.

This research implies that when designing a learning environment for local and international students discussing in ELF, it is important to let the local students prepare for the discussion not only by studying English, but also by encouraging them to think about the topic to make sure they know what they would like to say in the conversation. The results of this study suggest the importance of content understanding in preparation activities for ecological CALL and EMI classes. In an ecological CALL environment, it is implied that technology helps the learners to lower their affective barriers and improve their attitudes toward the use of English when participating in the conversations as global citizens. This study suggests that preparing the learners for discussion by encouraging them to have things to communicate may enhance their participation in ELF conversations, resulting in the maximization of the effectiveness of the learning environment. As suggested in the introduction, teachers designing the intercultural collaboration using CALL environment also can make use of this study. For example, studies of flipped classrooms for language learning include preparation activities such as watching videos in the target language [42] or studying English idioms through verbal and written online communication [43]. However, it might be effective to allow the students to watch the video even in their native language to ensure the students' full understanding of the material content to increase their participation in intercultural discussions.

Meanwhile, it is important to analyze why the number of utterances by participants did not increase dramatically. The authors propose three tentative explanations for this, which can also be considered to indicate the limitations and directions of future improvements in this research.

First, some participants did not have enough CSs to fully participate in the discussion. The Content Group showed the use of CSs to achieve communication in English and the number of utterances did not increase drastically because the participants spent time figuring out their wording. At the same time, novice English learners would not have enough CSs to participate in the discussions. It would be effective to teach learners CSs or support their use of CSs.

Second, it was difficult to control other variables affecting the state WTC, especially the properties of the interlocutors. Some of the interlocutors tended to ask many open-ended questions and helped the participants to speak up, while others were not as enthusiastic in encouraging their partners to talk in English. In addition, there were some interlocutors who were so eager to talk about themselves that the participants did not get enough time to talk. Teaching interlocutors how to collaborate and co-construct a conversation can help resolve this issue.

Further research with more participants is needed to corroborate the results of this study. WTC usually does not focus on the quality of communication behavior as it is more like a predictor of the amount and frequency of communication; therefore, conversation analysis was not carried out in this study. However, qualitative conversation analysis might be suggested in future studies to understand participants' degree of participation.

State WTC is still under investigation. Further studies of state WTC and student participation in 
ELF discussion may shed light on, for example, the relationship between students' language proficiency and their performance. In addition, future studies can consider developing a method to increase state WTC in an online setting based on the results of our research as the opportunity for online classes increases due to the global pandemic of COVID-19.

\section{Acknowledgement}

The authors are grateful to Professor Yoko Hasebe of Keio University for the useful discussions. We gratefully acknowledge the cooperation of the participants and interlocutors. We would like to thank Editage (www.editage.com) for the English language editing.

\section{Author's Note}

This paper is modified by adding new information to our presentation "Preparation to Enhance Japanese University Students' Participation in ELF dyadic discussion" at the 55th RELC International Conference, 2021.

\section{References}

[1] D.M. Chun, "The role of technology in SLA research," Language Learning \& Technology, vol. 20 , no. 2, 2016, pp. 98-115.

[2] M. Warschauer, "Technological change and the future of CALL," S. Fotos and C. Brown, eds, New perspectives on CALL for second language classrooms, Routledge, 2004, pp. 27-38.

[3] C.A. Hafner, A. Chik, and R.H. Jones, "Digital literacies and language learning," Language Learning \& Technology, vol. 19, no.3, 2015, pp. 1-7.

[4] D. Zheng, M.F. Young, R.A. Brewer, and M. Wagner, "Attitude and self-efficacy change: English language learning in virtual worlds," CALICO journal, vol. 28, no. 1, 2009, pp. 205231.

[5] J. Vinther, "Enhancing motivation with cultural narratives in computer-mediated communication," Computer Assisted Language Learning, vol. 24, no. 4, 2011, pp. 337-352.

[6] J.J. Chen and S.C. Yang, "Promoting cross-cultural understanding and language use in research-oriented Internet-mediated intercultural exchange," Computer Assisted Language Learning, vol. 29, no. 2, 2016, pp. 262-288.

[7] Z. Dörnyei, "Attitudes, orientations, and motivations in language learning: Advances in theory, research, and applications," Language learning, vol. 53, no. suppl. 1, 2003, pp. 3-32.

[8] H. Reinders and S. Wattana, "Affect and willingness to communicate in digital game-based learning,” ReCALL, vol. 27, no. 1, 2015, pp. 38-57.

[9] N. Chotipaktanasook, "Using social media in the EFL classroom for the enhancement of low affective filter and willingness to communicate," Proceedings of CLaSIC, 2016, pp. 56-64. 
[10] K. Nakaya and M. Murota, "Development and Evaluation of an Interactive English Conversation Learning System with a Mobile Device Using Topics Based on the Life of the Learner," Research and Practice in Technology Enhanced Learning, vol. 8, no. 1, 2013, pp. 65-89.

[11] E. Ayedoun, Y. Hayashi, and K. Seta, "Web-services Based Conversational Agent to Encourage Willingness to Communicate in the EFL Context," The Journal of Information and Systems in Education, vol. 15, no. 1, 2016, pp. 15-27.

[12] H. Rose and J. McKinley, "Japan's English-medium instruction initiatives and the globalization of higher education," Higher Education, vol. 75, no. 1, 2018, pp. 111-129.

[13] J. Dearden, "English as a medium of instruction-a growing global phenomenon," 2014; https://www.teachingenglish.org.uk/sites/teacheng/files/pub_E484\%20EMI\%20-\%20Cover \%20option_3\%20FINAL_Web.pdf.

[14] S. Lin, "To speak or not to speak in the new Taiwanese university: class participation and identity construction in linguistically and culturally diverse graduate classrooms," Language and intercultural communication, vol. 18, no, 2, 2018, pp.184-203.

[15] J.C. McCroskey, "Reliability and validity of the willingness to communicate scale," Communication Quarterly, vol. 40, no. 1, 1992, pp. 16-25.

[16] J.C. McCroskey and V. P. Richmond, "Willingness to communicate: A cognitive view," Journal of Social Behavior \& Personality, vol. 5, no. 2. 1990, pp. 19-37.

[17] P.D. MacIntyre, R. Clément, Z. Dörnyei, and K.A. Noels, "Conceptualizing willingness to communicate in a L2: A situational model of L2 confidence and affiliation," The Modern Language Journal, vol. 82, no. 4, 1998, pp. 545-562.

[18] J.E. Peng and L. Woodrow, "Willingness to communicate in English: Amodel in the Chinese EFL classroom context," Language learning, vol. 60, no. 4, 2010, pp. 834-876.

[19] J. Zhang, N. Beckmann, and J.F. Beckmann, "To talk or not to talk: A review of situational antecedents of willingness to communicate in the second language classroom," System, vol. 72, 2018, pp. 226-239.

[20] S. Amano, "Reducing Unwillingness to Speak English by Using Total Physical Response Activities in a Japanese University Context (Theoretical Studies and Experimental Studies, The 43rd CELES Conference in Toyama)," Journal of the Chubu English Language Education Society, vol. 43, 2014, pp. 153-160.

[21] J. Fukuta, "Does the English Language Lesson with Communicative Tasks Reduce Unwillingness to Speak English? : A Practical Report,” LET Journal of Central Japan, vol. 26, 2015, pp. 85-94.

[22] T. Isoda, “Reducing EFL Learners' Unwillingness to Speak English,” JACET Journal, vol. 48, 2009, pp. 53-66.

[23] Y. Cao, "Investigating situational willingness to communicate within second language 
classrooms from an ecological perspective," System, vol. 39, no. 4, 2011, pp. 468-479.

[24] M. Eddy-U, "Motivation for participation or non-participation in group tasks: A dynamic systems model of task-situated willingness to communicate," System, vol. 50, 2015, pp. 4355.

[25] S.J. Kang, "Dynamic emergence of situational willingness to communicate in a second language,” System, vol. 33, no. 2, 2005, pp. 277-292.

[26] Z.M. Khazaei, A.M. Zadeh, and S. Ketabi, "Willingness to Communicate in Iranian EFL Learners: The Effect of Class Size," English Language Teaching, vol. 5, no. 11, 2012, pp. $181-187$.

[27] M. Yu, "An examination of the dynamic feature of WTC through dyadic group interaction," System, vol. 55, 2015, pp.11-20.

[28] L. Buckingham and R.S. Alpaslan, "Promoting speaking proficiency and willingness to communicate in Turkish young learners of English through asynchronous computer-mediated practice," System, vol. 65, 2017, pp. 25-37.

[29] M. Freiermuth and D. Jarrell, "Willingness to communicate: can online chat help?," International journal of applied linguistics, vol. 16, no. 2, 2006, pp. 189-212.

[30] M. Fujii and R. Nomura, Presentation in English: Ready to use expressions, Nikko Kikaku, 2003.

[31] K. Hinata and M. Kano, 20 Unknown skills of English conversations, DHC, 2010.

[32] Ministry of Education, Culture, Sports, Science and Technology, "Table comparing each qualification examination and CEFR," 2018; https://www.mext.go.jp/b_menu/houdou/30/03/ _icsFiles/afieldfile/2019/01/15/1402610_1.pdf.

[33] Council of Europe, "Common European Framework of Reference for Languages: Learning, teaching, assessment - Companion volume," Council of Europe Publishing, 2020.

[34] T. Yashima, "International posture and the ideal L2 self in the Japanese EFL context," Motivation, language identity and the L2 self, vol. 86, no. 1, 2009, pp. 144-163.

[35] S. Ishihara and Y. Kinoshita, "Filler words as a speaker classification feature," SST 2010, 2010, pp. 34-37.

[36] T. Sadanobu, "Uttering Fillers in Conversation ( $<$ Feature Articles $>$ Conversational Speech)," Journal of the Phonetic Society of Japan, vol. 14, no. 3, 2010, pp. 27-39.

[37] Z. Dörnyei, “On the teachability of communication strategies," TESOL quarterly, vol. 29, no. 1,1995 , pp. 55-85.

[38] A. Mizumoto and O. Takeuchi, "Basics and Considerations for Reporting Effect Sizes in Research Papers," Studies in English Language Teaching, vol. 31, 2008, pp. 57-66.

[39] M. Canale and M. Swain, "Theoretical bases of communicative approaches to second 
language teaching and testing," Applied linguistics, vol. 1, no, 1, 1980, pp. 1-47.

[40] C. Færch and G. Kasper, "Two ways of defining communication strategies," Language learning, vol. 34, no. 1, 1984, pp. 45-63.

[41] Y. Fang, "Lexical Problem-Solving Communication Strategies Employed by Chinese Japanese Learners," Studies in Japanese Language and Japanese Language Teaching, vol. 3, 2012, pp. 127-143.

[42] J. Mehring, "Present Research on the Flipped Classroom and Potential Tools for the EFL Classroom," Computers in the Schools, vol. 3, no. 1, 2016, pp. 1-10.

[43] J.S.C. Hsieh, W.C.V. Wu and M.W. Marek, "Using the flipped classroom to enhance EFL learning," Computer Assisted Language Learning, vol. 30, nos. 1-2, 2017, pp. 1-21. 